\title{
HPV Regulatory Protein E2 Antibody
}

National Cancer Institute

\section{Source}

National Cancer Institute. HPV Regulatory Protein E2 Antibody. NCI Thesaurus. Code C124259.

Any immunog lobulin that recognizes human papillomavirus regulatory protein E2. 